\title{
Mechanism based on social factors student population crisis
}

\author{
Lianjing Zhou \\ Life of Sciences \\ Beijing Institute of Technology \\ Beijing, China
}

\author{
Yan Chen, Zhixiang Li \\ Beijing Institute of Technology Management and \\ Economics \\ Beijing, China
}

\author{
Xiaohui Lian \\ China North Industries Group Corporation,NorincoGroup \\ Beijing, China
}

\begin{abstract}
- college students as an important part of the social groups, to a large extent will be the influence and impact of social culture, morality, mentality, safety and employment, and is in a growing, and is likely to become pessimistic, negative, depression, loss, frustration, and even beyond the legal boundaries of impulsive behavior, triggering the events of the student population crisis, affecting social stability, the impact of the development and construction of the socialist cause. Article for the influence of social factors on college students, through literature induction, frequency analysis and Delphi method to analyze social research student population crisis mechanism, the establishment of China's social transition, the social mechanism of the student population crisis theory.
\end{abstract}

Keywords-Social factors; student population crisi; Mechanism

Along with the deepening of economic reform and social reform, the reform of higher education in China are rapidly advancing, showing the management of a social approach to diversification in the form of school and students diversifying the structure of the situation, making campus and Social gradual integration of cross-cutting.[1]. Shorten social time for college students this situation has created favorable conditions. However, intense cultural conflict, makes the whole social values, norms, guidelines adjustments and changes in social values and behavior has undergone great changes. People's values have gradually become relative and pluralistic values. Diverse, heterogeneous and cultural trends influx, the old value system shaken, but not the formation of a more mature new value system, which caused by the coexistence of old and new ideas college students ideological confusion, confused, disoriented [2]. Especially in the social depth of the transition period, the college students as a member of the society, social factors and psychological behavior of students will have an important impact. When college students face real-life difficulties, contradictions and social injustices, they will always appear impulsive and lead to mass crisis. Therefore, the social mechanism of college students study social transition crisis typical of the era and practical significance.

\section{RESEARCH METHODS}

Papers using modified Delphi method [3] screening indicators to identify indicators of weight. Delphi method is an intuitive forecasting techniques developed by the RAND Corporation in the United States in the 1940s, research carried out by experts collective evaluation methods. It is usually anonymous, after a 3-4 round of expert inquiry concerning control, seek professional advice, expert opinion of the organizers of each round pooled analysis, after many rounds of letter of inquiry, making experts convergence of views, and finally according to the opinion of the experts, to evaluate the evaluation object is a combination of quantitative and qualitative prediction, evaluation methods [4-6]. This method has been widely used in the field of management, sociology and research, and is considered to be an effective assessment and management methods.

Modified Delphi method adopted is to seek expert advice in the design of expert advice before the table, prior to the relevant experts in the consultation process to provide the background information of the study, the experts can analyze the judgment based on the facts. In this way, you can reduce the number of reincarnation. Modified delphi method to select the experts, not randomly selected, but the purpose of directional selection, to ensure that the experts elected with a strong representative. Select the number of experts is generally believed that about 15-50 appropriate

Through purposeful program selection method, according to experts filter criteria, select the crisis of college students are more familiar with, and have practical experience of Student Management experts.

\section{RESEARCH PROCEDURES}

\section{A. Establishment of Delphi Advisory Group of Experts}

Experts are composed of five persons engaged in education and teaching in colleges and universities, including 3 professors or leaders of the school, associate professor level cadres. 


\section{B. Index for}

Frequency analysis, prepared by the literature of inductive and comparative analysis theoretical system, and submitted to the consultants, focus group interviews.

\section{Selection of Experts}

Select a number of experts who are engaged in crisis intervention research or education management in universities Expert standard: associate professors or sub-division level and above positions; treat consulting more familiar; Education teaching more than 5 years.

\section{Preparation of the Expert Advisory Table}

The expert advisory Table is designed to open, experts of index additions and modifications, indicating the basic situation of the thesis and explanatory notes; same time, part of the design of open-ended questions

\section{E. First Round of Expert Advice}

Experts to fill in the inquiry form to answer open-ended questions. Through the first round of expert advisory activities, evaluation, selection of indicators in the beginning of the proposed index system.

\section{F. Improve the Consultation Scale}

Scale data analysis of the first round of expert advice and expert opinion, to amend the contents of consulting Scale, and the preparation of the second round of expert advisory scale.

\section{G. Second Round of Expert Advice}

Revise and improve the scale, to carry out a second round of expert consultation. Then statistics and analysis data.

\section{BEGINNING OF THE PROPOSED INDICATORS}

Papers in the process of writing, collecting the 1978-2008 central ministries issued to strengthen and improve ideological and political education literature and in 16th and 17th Central Party Congress report, the past five years, Beijing, Shanghai,Tianjn, Chongqing Party Congress report, analysis of the focus of the work of the central and four municipalities, frequency analysis of the social factors of the depth of the transition the student population crisis.

\section{A. Frequency Analysis}

\section{1) Analysis of government documents}

The resumption of college entrance examination in China since the reform and opening up, the CPC Central Committee issued special documents to strengthen ideological and political work, a total of four, in varying degrees, in different forms emphasized moral education, culture, public opinion to guide the internal and external environment construction aspects of the employment of university students as well as various security mechanisms. The following as the main factor to the social, cultural, social, public opinion, social security, employment, social ethics, social security, the frequency analysis of the social causes of the student population crisis. After, 1978 - 2008, the central authorities issued four reports on the frequency of the ideological and political work special documents covered by the social factors and the CPC Central Committee and the State Council ministries and commissions issued with respect to these six areas the number of special documents grouped together in Table 1

2) Government report analyzes

The papers collected in the process of writing the report of the 16th and 17th the previous report of the meeting of the CPC Central Committee since the 17th Session of the four municipalities of Beijing, Shanghai, Tianjin, Chongqing, and various reports were analyzed, developed a student population crisis of the social causes of frequency, as shown in Table 1.

TABLE I. CEntral Document AND PARTy Congress Report Social Factors Frequency Table

\begin{tabular}{|c|c|c|c|c|}
\hline No. & Social Causes & $\begin{array}{l}\text { Special documents frequency } \\
\text { times }\end{array}$ & $\begin{array}{l}\text { number of ministries } \\
\text { documents }\end{array}$ & Reporting rate \\
\hline 1 & Social and cultural & 4 & 7 & 29 \\
\hline 2 & Social public opinion & 4 & 7 & 10 \\
\hline 3 & Social Security & 4 & 8 & 29 \\
\hline 4 & Social employment & 4 & 6 & 29 \\
\hline 5 & Social and moral & 4 & 13 & 26 \\
\hline 6 & Social Security & 2 & 1 & 32 \\
\hline
\end{tabular}

Analysis can be seen from the central ministries files and municipalities directly under the Central Government report, since the reform and opening up, the central ministries issued a document for the ideological and political education work, on culture, public opinion, security, employment, moral file have 10above, relating to the protection of the file; 32 reports of the central government and municipalities, cultural, security, employment, ethics, protection in more than 20. On the whole, the contents of the documents of the social aspects of public opinion is relatively small, but taking into account the network, the information age, social public opinion crises, evolution will play an important role, papers on the basis of frequency analysis times, the six aspects of the preliminary view that triggered the crisis of the student population has a certain role.

\section{B. Literature Summarized Study}

Since the reform and opening up, China's remarkable achievements in the political, economic, social, cultural and other fields, is currently experiencing a critical period of 
economic transition, social transformation, during this period, often prone to economic dislocation, social disorder, psychological imbalance, behavior Exemplary status. Induction through literature, summed up the results of a number of scholars and researchers, groups crisis social factors can be attributed eight aspects of the social structure, social security, social management, social ethics, social organizations, social systems, social, cultural, social public opinion.

\section{Comparative Study}

The comparative analysis is the most common method of statistical research, as a statistical calculation of the relative indicators, or as a statistical analysis method, it is statistically occupies an important position. Comparative analysis, also known as comparative analysis, two or more than two contact number of indicators compared to analyze the contradictions between the various phenomena and relationships. Comparative analysis needs to have a basis for comparison, that is, what indicators as the basis for comparative analysis [7]. In related studies, in order to reach statistical data mining, to study the number of social phenomena, the purpose, often inseparable from the comparative analysis.

The comparative analysis is the most common method of statistical research, as a statistical calculation of the relative indicators, or as a statistical analysis method, it is statistically occupies an important position. Comparative analysis, also known as comparative analysis, two or more than two contact number of indicators compared to analyze the contradictions between the various phenomena and relationships. Comparative analysis needs to have a basis for comparison, that is, what indicators as the basis for comparative analysis [7]. In related studies, in order to reach statistical "data mining", "social comparison frequency analysis and literature summarized the conclusions obtained, we can find socio-cultural, social public opinion, social, moral, social security in the conclusions of the two methods are pointed out that social security is one aspect of social management, social employment in the two methods did not coincide However, due to the end of the last century large-scale enrollment of higher education in China, the increase in the number of university graduates in this case, in the context of the global financial crisis, resulting in the employment of college graduates has become the focus of attention has also become a key factor in the Cause of College Student discontent, employment and social structure and social organization have a certain relationship. the social machine reasons of social public opinion, social security, social, moral, social security, employment, social and cultural contrast to the conclusions of the analysis of the two methods, the paper tentatively set the transition period the student population crisis six areas constitute the same time, the current socio-cultural aspects, film and television work, and web content greater impact on college students, the decomposition of the cultural training mechanism; national culture and outstanding cultural heritage, cultural heritage decomposition mechanism; attraction and manifestations of cultural content, the decomposition of the mechanisms of cultural innovation in society public opinion, the channels and expression for the expression of public opinion, public opinion development mechanism; decomposition for a positive response to public opinion and divert negative public opinion, the decomposition of public opinion guidance mechanism; decomposition of public opinion for the disposal of public opinion, and respond to emergencies, emergency response mechanism. In social security, physical security and personal safety for college students, the decomposition of the security mechanism; Helping universities and social system and emergency measures, the decomposition of the safety relief mechanism; around the campus environment and order situation, the decomposition of the integrated governance mechanisms in social employment, employment assistance and vocational training system decomposition mechanism of employment services; the decomposition of the mechanism of market development for college students employment opportunities and employment equity issues; the applicability and students of university teaching content knowledge improve the quality of the decomposition mechanism for education reform in the social and moral aspects of the realization of the performance of the party members and cadres and government agencies, the decomposition mechanisms of moral education; decomposition awareness training mechanism for advanced socialist theory and practice; for on the carry forward of righteousness and evil punished, the decomposition of the social reward and punishment mechanism, the decomposition of the income distribution mechanism for the income gap in the social and regional development disparities in social security; expression for the interests of the masses, and adjust the balance, decomposition the interests of security mechanisms; medical and health system and housing traffic conditions, the decomposition of the public service mechanism.

\section{IV.STATISTICAL ANALYSIS}

Through two rounds of expert consultation, to obtain a secondary index system survey data, and then using SPSS19.0 software for statistical analysis to calculate the number of indicators, importance, familiarity, standard deviation, one, two level indicators of the degree of expert authority, and for the chi-square test. According to the experts rated the importance of indicators, the primary and secondary indicators calculated weight coefficient. After the end of the second round of consultation, according to the experts rated the importance of indicators, calculation, weight coefficients of the two indicators. According to experts, the indicators familiarity score, to evaluate the degree of expert authority.

\section{A. Importance and Familiarity}

The importance and familiarity of the two expert advisory results are shown in Table 2 . The importance of an indicator system mean all greater than 3.8 , the total mean of the five indicators of the degree of importance is greater than 4 , the experts believe are important indicators for the crisis of the student population. An index system familiarity mean all greater than 3.5, five indicators of the importance of the 
total mean of 3.5 , the experts on five indicators are more familiar. The results show that the Social Security were the lowest in importance and familiarity, and close to the median level.

The analysis shows the importance scale, the highest value of the social public opinion, social security, the lowest value; familiarity scale, the highest value of the social employment, social security, the lowest value.
Expert attitude difference analysis: independent samples T-test method, different title (position) in the first round of the survey sample, different work experience expert analysis, testing the differences of the different groups. The results show that the analytical data of the various types of expert knowledge of the level indicator of the degree of importance are greater than 0.05 , indicating no significant difference between the two types of expert

\section{B. Difference Analysis of the Different Groups}

TABLE II. DEgREeS AND FAMILIARITy MEAN TABLES

\begin{tabular}{|c|c|c|c|c|c|}
\hline $\begin{array}{l}\text { Importance } \\
\text { Theoretical system }\end{array}$ & First & Second & $\begin{array}{l}\text { Familiarity } \\
\text { Theoretical system }\end{array}$ & First & Second \\
\hline Social cultural & 4.0476 & 4.2273 & Social cultural & 3.9524 & 3.8182 \\
\hline Social public opinion & 4.3333 & 4.5909 & Social public opinion & 3.8095 & 3.5909 \\
\hline Social employment & 4.2857 & 4.3182 & Social employment & 4.2857 & 3.7727 \\
\hline Social moral & 3.9524 & 4.5000 & Social moral & 4.0000 & 4.1364 \\
\hline Social Security & 3.8095 & ---- & --- & 3.5714 & --- \\
\hline
\end{tabular}

understanding. Different gender expert level indicators important the variance equation inspection, sig is 0.015 , less than the standard value of 0.05 . There is a significant difference between male and female expert knowledge of the level indicator importance degrees, as shown in Table 3. The requirements in the second round of expert advice, the selection of experts should pay attention to gender balance.
Balance the number of male and female experts to analyzethe collected data of the second round of expert advice, the different groups of experts on the understanding of the importance and familiarity of the index system has no significant difference, and also shows the theoretical system construction is reasonabl.

TABLE III. FIRST CONSUlting GeNDER DifFERENCES IN THE INDEPENDENT SAMPLE TEST SHEET

\begin{tabular}{|c|c|c|c|c|c|c|c|c|c|c|}
\hline & & \multicolumn{2}{|c|}{$\begin{array}{c}\text { Variance equation } \\
\text { inspection }\end{array}$} & \multicolumn{7}{|c|}{ T-test of the mean equation } \\
\hline & & \multirow{2}{*}{$\mathrm{F}$} & \multirow{2}{*}{ Sig. } & \multirow{2}{*}{$\mathrm{t}$} & \multirow{2}{*}{ df } & \multirow{2}{*}{ Sig. } & \multirow{2}{*}{$\begin{array}{c}\text { Mean } \\
\text { difference }\end{array}$} & \multirow{2}{*}{$\begin{array}{l}\text { Standard } \\
\text { error }\end{array}$} & \multicolumn{2}{|c|}{$95 \%$ confidence interval differential } \\
\hline & & & & & & & & & Lower limit & Upper limit \\
\hline \multirow{2}{*}{$\begin{array}{l}\text { Importa } \\
\text { nce }\end{array}$} & $\begin{array}{l}\text { Assuming that the } \\
\text { variance is equal }\end{array}$ & 6.095 & .015 & -2.10 & 124 & .037 & -.42292 & .20087 & -.82049 & -.02535 \\
\hline & $\begin{array}{l}\text { Assume that the } \\
\text { variance is not equal }\end{array}$ & & & -2.83 & 92.04 & .006 & -.42292 & .14926 & -.71936 & -.12648 \\
\hline \multirow{2}{*}{$\begin{array}{l}\text { Familia } \\
\text { rity }\end{array}$} & $\begin{array}{l}\text { Assuming that the } \\
\text { variance is equal }\end{array}$ & .126 & .724 & .483 & 124 & .630 & .08125 & .16822 & -.25171 & .41421 \\
\hline & $\begin{array}{l}\text { Assume that the } \\
\text { variance is not equal }\end{array}$ & & & .495 & 50.47 & .623 & .08125 & .16418 & -.24844 & .41094 \\
\hline
\end{tabular}

Index system of differential analysis: using ANOVA the SPSS19.0 software consulting a scale indicator system between the relevance test, to obtain comparative results for the difference, as shown in Table 4. The first round of consultation experts on social security and social employment familiarity significant difference means that the experts believe that social security and social employment between associated. Taking into account the observations and recommendations of the expert feedback, to delete an indicator of social security, and increase the entrepreneurial secondary indicators. The difference between two index system of analysis, the results show significant values were greater than 0.05 , indicating no significant correlation between. After the second round of expert advice, data analysis, significantly greater than 0.05 , indicating negative correlation between, there is no significant difference.

\section{CONCLUSION}

Two consultants and a higher authority, there was no significant difference in understanding of the different categories of experts on the index system, expert opinions coordination. Therefore, after use literature summarized method and frequency analysis method initially built the transition student population crisis of the social mechanism, using the Delphi method, expert advice to do a further improve and verify the final build from the crisis of China's transition college students groups system of social theoretical. The system includes five a theoretical system and 16 two theoretical system. As shown in Figure 1. In addition, according to the importance of the outcome of the expert consultation, in the current information age, social public opinion, the greatest impact on the student population, but also easily lead to mass crisis. 


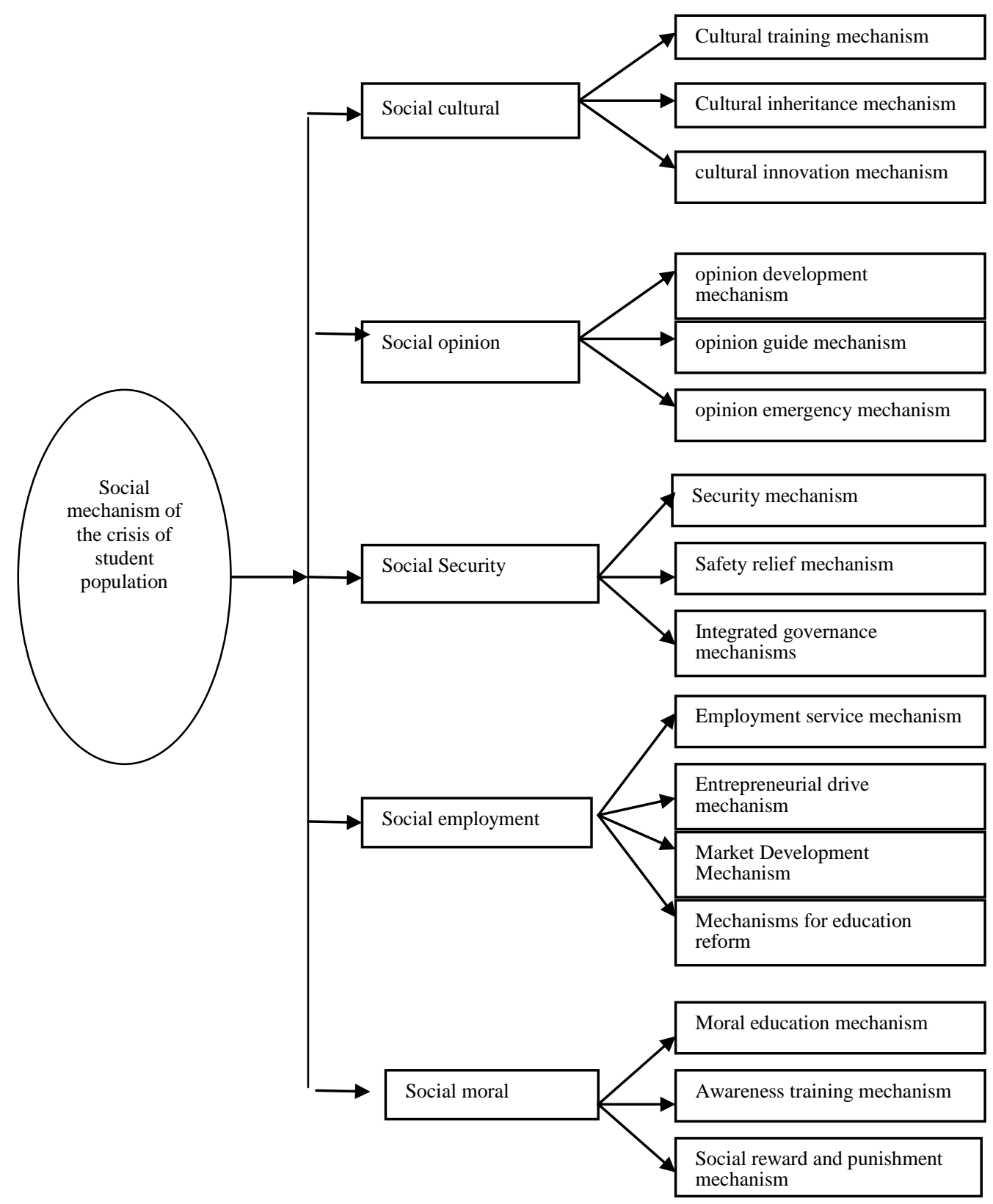

Figure 1. Social transition a student population crisis mechanism of social

\section{ACKNOWLEDGEMENT}

This is one of the initial results of the Ministry of Education, Humanities and Social Sciences Youth Fund (11YJC630024)

\section{REFERENCES}

[1] Jingxuan Wang. Transition social crisis multiple cause analysis. Chinese business[J].2009.
[2] Xiangyu He. Students ' social problems in a harmonious society. China Economic Times Press .2009.

[3] Guang zeng. Modern epidemiological methods and applications. Beijing Medical University and Peking Union Medical College Press .1996,250-270

[4] Beech B .Go the extra mile-use the Delphi technique. Journal of Nurse man [J].1999

[5] Long T, Johnon M. Research in nurse education today do we meet our aims and scope? Nurse Education Today.2002 
[6] Amold Leving A model for health projections using knowledgeable information. World Health Statistic Quart.1984

[7] Cui Zhen Lin. comparative analysis in the food statistical analysis. Heilongjiang Grain and Oil Technology [J].2000.2 